\title{
O efeito moderador da concentração de investidores institucionais na relação entre surpresa nos lucros e retornos anormais
}

\author{
Éverton Galhoti Coelho' ${ }^{\text {(D) , Romualdo Douglas Colauto }}{ }^{2}$ \\ Universidade Federal do Paraná. Curitiba, Brasil.
}

$凶$

'evertongalhoticoelho@gmail.com

2rdcolauto.ufpr@gmail.com

Editado por:

Orleans Silva Martins

Paulo Roberto da Cunha

\section{Resumo}

Objetivo: $O$ estudo analisa o efeito moderador da concentração de investidores institucionais na relação entre surpresa nos lucros e retornos anormais em companhias brasileiras de capital aberto.

Método: Os dados foram coletados no banco de dados da Thomson Reuters ${ }^{\circledR}$. $\bigcirc$ investidor institucional é tratado nessa pesquisa como um acionista que detém ações ordinárias e atua com ativos sob gestão (Assets Under Management - AUM). A surpresa nos lucros foi computada pela diferença entre o lucro divulgado pela companhia e o estimado pelo consenso dos analistas. Os retornos anormais foram calculados pelo método de Estudo de Eventos. As análises foram pautadas em regressões multivariadas com estrutura de painel. Foram investigadas 118 companhias listadas na B3 durante o período de 2010 a 2018, totalizando 2.264 observações.

Resultados: Os resultados confirmaram que a surpresa positiva de lucro é capaz de gerar retornos anormais positivos após a divulgação dos resultados contábeis trimestrais. No entanto, o efeito moderador da concentração de investidores institucionais sobre a relação surpresa-retorno foi inconclusivo, pois não foram encontradas evidencias estatísticas de que a concentração dos investidores institucionais possa alterar a direção ou a força que a surpresa positiva dos lucros causa nos retornos anormais.

Contribuições: O estudo contribui para o entendimento do papel dos investidores institucionais no mercado de capitais ao analisar se a sofisticação financeira atribuída a estes investidores é suficiente para diminuir as anomalias no preço das ações provocadas pelas surpresas nos lucros.

Palavras-chave: Legal enforcement. Corporate governance. Corporate performance.

\section{Como citar:}

Galhoti Coelho, Éverton, \& Colauto, R. D. O EFEITO MODERADOR DA CONCENTRACC̃O DE INVESTIDORES INSTITUCIONAIS NA RELAÇÃO SURPRESA NOS LUCROS E RETORNOS ANORMAIS. Advances in Scientific and Applied Accounting, 14(2), 003-015 / 016. https://doi.org/10.14392/ asaa. 2021140201 


\section{Introdução}

O mercado de capitais nacional e internacional é sensível às surpresas nos lucros (Bernard \& Thomas, 1989; Foster et al., 1984; Skinner \& Sloan, 2002), mas pouco se sabe se o tipo de investidor que compõe a estrutura de propriedade da companhia interfere no retorno das ações diante de uma surpresa nos lucros. Martinez (2006), Pimentel (2015) e Galdi e Lima (2016) inferiram que o mercado brasileiro tem pago um prêmio para as companhias que conseguem atingir com alusiva precisão as estimativas dos analistas sobre os lucros futuros. Porém, acredita-se que os investidores institucionais, por serem considerados participantes sofisticados do mercado de capitais, tendem a fazer projeções de melhor qualidade a partir do lucro divulgado pelas companhias e, consequentemente, não se surpreendem de forma a causar reação exagerada no retorno das ações.

O lucro por si só pode não ser capaz de provocar mudanças nas perspectivas do investidor, pois sob a lógica do mercado eficiente não há chances para retornos anormais decorrentes de informações públicas. Isso porque os preços já refletiram todas as informações disponíveis, ou seja, os anúncios de lucro/prejuízo não deveriam impactar nos preços, exceto se o anúncio surgisse de forma diferente das expectativas previstas pelo mercado.

Martinez (2006) menciona que uma proxy comum para a expectativa do mercado é a previsão dos analistas, sendo que resultados reais acima dos previstos são considerados surpresas positivas. Por outro lado, quando as companhias não alcançam as previsões dos analistas, essas são denominadas surpresas negativas e refletem imediatamente no valor das ações. Seria como se o mercado punisse as companhias que não performam nas expectativas dos analistas.

Nesse sentido, os gestores podem se aproveitar das ineficiências dos investidores para atingir a expectativa do lucro estimada pelos analistas, utilizando do artifício de gerenciamento de resultados. De acordo com Graham et al. (2005), os Chief Financial Officer (CFO's) farão - possível para atingir as metas de lucro dos analistas, pois há receio de que as metas de lucros não atingidas ou lucros irregulares possam afetar a confiança dos investidores e a estabilidade financeira da empresa. No entanto, pode-se intuir que os investidores institucionais sejam menos sensíveis às surpresas nos lucros em função de sua sofisticação na análise dos dados divulgados pelas companhias.
Jiang et al. (2008) expressam que companhias com altas concentrações de propriedade institucional mitigam o comportamento oportunista dos gerentes, pois exercem uma espécie de governança corporativa externa, que desencoraja os gestores a utilizarem práticas de manipulação do lucro contábil. Além disso, Boehmer e Kelley (2009) estudaram o comportamento das ações ordinárias "intraday" durante vinte e dois anos da NYSE e concluíram que as ações com maior propriedade institucional são precificadas de forma mais eficiente. Os resultados apontaram que o papel dos acionistas institucionais atenua as anomalias no preço das ações e do retorno, além de acelerar o ajuste de preços às novas informações.

Assim, considerando a necessidade de aprofundar a discussão sobre o impacto que os investidores institucionais podem causar no mercado de ações brasileiro, esta pesquisa tem como propósito responder a seguinte inquietação: qual o efeito moderador da concentração do investidor institucional na relação entre surpresa nos lucros e retornos anormais em companhias brasileiras de capital aberto?

Apesar de as pesquisas internacionais estudarem a relação lucro-retorno a mais de quarenta anos, os estudos no Brasil ainda são incipientes. Aprofundar a temática para compreender melhor a reação dos investidores perante a relação dos anúncios dos números contábeis sobre o mercado de capitais representa uma das contribuições deste estudo. Ressalta-se que não foram encontrados estudos que verificassem 0 impacto dos investidores institucionais nos retornos anormais frente às surpresas nos lucros. Por isso, a pesquisa ganha importância para mercados emergentes.

A base de dados utilizada para coleta dos investidores institucionais dispõe de uma série histórica trimestral de ações ordinárias por investidor e não apenas dos principais acionistas como é comumente relatado nos Formulários de Referências (FR) divulgados na CVM. Esses dados são mais completos, pois além das informações sobre a estrutura de propriedade inferior a $5 \%$, compila dados divulgados pelos próprios investidores, o que permite análises mais completas, incluindo as participações dos investidores institucionais com baixa participação acionária.

Cabe destacar que no Brasil há altos índices de ações em posse de poucas companhias. Além disso, existe 
baixa liquidez e elevada volatilidade das ações, por conta dos movimentos especulativos, bem como pela concentração de investimentos em um único acionista majoritário (Pimentel, 2015). Tais características interferem na eficiência do mercado o que dificulta comparações com o mercado internacional.

\section{Fundamentação Empírica e Hipótese}

Sob a lógica da Hipótese do Mercado Eficiente (HME), as variações dos lucros contábeis só apresentariam conteúdo informacional na medida em que pudesse sinalizar a ocorrência de fluxos de caixa não esperados. Por isso, para que o mercado reagisse de forma significativa aos lucros reportados precisariam de um fator inesperado. Beaver et al. (1979) mostraram que quanto maior a surpresa nos lucros, maior a resposta do mercado. Isso porque os investidores, no momento da divulgação de lucro, ajustam a expectativa de desempenho das companhias.

A ideia é de que o lucro inesperado interfere na geração dos recursos financeiros futuros, e por isso, desperta a atenção dos investidores. De acordo com Alwathnani et al. (2017), os investidores, no momento de projetar perspectivas futuras das companhias, atribuem maior peso ao lucro contábil inesperado, por isso, as ações apresentam forte reposta, isto é, conduzem a retornos exagerados das ações.

Na forma semiforte da HME, os preços das ações respondem instantaneamente e imparcialmente à chegada de informações públicas. Os estudos de Ball e Brown (1968), Belo e Brasil (2006), Chudek et al. (2011), Foster et al. (1984) e Sarlo Neto et al. (2005) constataram atrasos consistentes nas respostas dos preços das ações às informações sobre os lucros, o que contraria a hipótese semiforte. Para Brown (1997), a prova da violação da HME em sua forma semiforte ocorreu por meio das pesquisas de Latané e Jones (1977), Jones et al. (1984) e Jones et al. (1985) que estudaram o efeito do lucro inesperado no preço das ações.

O conceito de Lucro Inesperado Padronizado (SUE), desenvolvido pela Latané e Jones (1977), baseiase no princípio de que as surpresas nos lucros são compreendidas como informações que podem justificar a revisão das crenças, por parte dos investidores, acerca da probabilidade de ganhos futuros. A lógica é que informações sobre a surpresa nos lucros e a revisão de crenças de probabilidade, que o acompanham, apresentam impactos mensuráveis nos preços das ações, em algum momento após o anúncio de lucros.

Estudos pregressos evidenciaram que o mercado reage e recompensa positivamente as companhias que atendem ou superam as previsões dos analistas. No entanto, é possível acreditar que nem todos os investidores confiam que os resultados divulgados estejam isentos de mensuração tendenciosa visando surpresas positivas. Bartov et al. (2002) explicam que os prêmios pagos às ações com surpresas positivas de lucro são justificados por razões econômicas, porém não se descarta a possibilidade de os gestores utilizarem de técnicas de gerenciamento de accruals para atingir metas previstas de lucro, como forma de provocar intencionalmente prêmios maiores para estas ações.

Segundo Hirshleifer et al. (2012) uma das premissas sobre as anomalias dos accruals (retardo na revisão dos preços das ações diante da informação sobre a magnitude dos accruals incluídos no lucro) é de que o mercado pode ser afetado pela baixa sofisticação financeira dos investidores. Isto é, os investidores são limitados para interpretar e precificar as informações contábeis. Martins et al. (2019) reforçam que os investidores não são qualificados o suficiente, ou ainda não se preocupam com a interferência proposital nos procedimentos para apuração do lucro e determinação dos fluxos de caixa futuro, o que provoca má precificação dos ativos (mispricing).

No entanto, acredita-se que a má precificação dos ativos, bem como, a melhora na interpretação dos procedimentos contábeis seja atenuada com a presença de investidores institucionais. O fato de os investidores institucionais serem considerados mais sofisticados, possibilita análises mais profundas e eficientes sobre as informações financeiras, - que por sua vez, contribui para mitigar anomalias provocadas pelas surpresas nos lucros. Green et al. (2011) constataram que a presença dos investidores institucionais no mercado americano reduziu as anomalias dos accruals. Por isso, espera-se que o mesmo efeito ocorra com as surpresas nos lucros.

Para Botelho (2019), uma das principais variações na cotação dos ativos em mercados de renda variável ocorre por conta da compra e venda realizada pelos investidores institucionais, sendo muitas vezes acompanhadas por outros investidores que buscam agir de forma conjunta. Dessa forma, os grandes movimentos de valorização e desvalorização podem ser resultados da tomada de decisão desse tipo de investidor. A movimentação de uma pessoa na bolsa de valores não consegue alterar o mercado, porém um fundo de previdência que decide 
mudar sua estratégia e comprar ações de determinada empresa de uma só vez, apresenta força suficiente de provocar alterações no preço de um ativo.

Vasconcelos e Martins (2020) argumentam que o papel dos investidores institucionais na incorporação de informações aos preços é um campo em expansão, não apenas no mercado brasileiro, mas em âmbito internacional, pois não existe um posicionamento definido se de fato os investidores institucionais incorporam informações aos preços das ações, ou ainda, se a presença de investidores institucionais aumenta a eficiência dos mercados com a rápida incorporação de informações especificas das companhias.

Teoricamente, grande parte da informação contida no lucro já está precificada antes mesmo de sua divulgação (Ball \& Brown, 1968), sendo a surpresa nos lucros responsável pelo fornecimento de novas informações ao mercado e pelo direcionamento no preço das ações. Todavia, um elemento exógeno pouco investigado, a participação de investidores sofisticados no quadro societário das companhias, pode fazer diferença na forma como a informação da surpresa nos lucros é processada pelo mercado.

Evidências empíricas apoiam a ideia de que investidores individuais geram padrões de retorno anormais antes dos anúncios de lucros, enquanto os investidores institucionais são mais propensos a detectar informações relacionadas a qualidade do lucro (Liu, 2018). Portanto, a hipótese do estudo prevê que: a concentração de investidores institucionais modera negativamente a relação entre surpresa positiva dos lucros e retornos anormais.

\section{Metodologia}

Este estudo utiliza como população alvo as companhias de capital aberto, exceto as do setor financeiro, que apresentaram ações negociadas na B3 (Brasil, Bolsa, Balcão) entre os trimestres de 2010 a 2018. Para a definição do período do estudo, levou-se em consideração à adoção das IFRS (International Financial Reporting Standards) que para as companhias brasileiras ocorreu em 2010. Além disso, o emprego de períodos anteriores a 2010 poderia causar danos de difícil controle na apuração do lucro contábil, tendo em vista as mudanças normativas com a convergência das IFRS (Martins et al., 2019).

A composição da amostra parte da perspectiva de um painel com dados trimestrais desbalanceado. O período do estudo perfez 33 trimestres, sendo que, a coleta foi realizada em janeiro de 2019. Os dados financeiros e sobre a estrutura de propriedade foram coletados no banco de dados da Thomson Reuters ${ }^{\circledR}$. O recorte populacional para a definição da amostra partiu de 312 companhias não financeiras listadas na B3. Posteriormente, foram excluídas as companhias que não apresentaram dados completos, resultando em 118 companhias e 2264 observações como amostra final.

\subsection{Varióvel Dependente}

Utilizou-se o retorno anormal para capturar a reação do mercado frente às surpresas nos lucros e o método de Estudo de Eventos foi empregado para verificar o impacto dos anúncios do lucro sobre a valoração das ações. Para a operacionalização do Estudo de Eventos foram seguidas as recomendações de (Barros et al., 2019; Champbell et al., 1997; Lima et al., 2008; Martinez, 2006; Paulo et al., 2013; Schimmer et al., 2015). Para o cálculo do Retorno Anormal foi utilizado o Aplicativo Eventstudytools, que se refere a um WEB APIs para a automatização da extração de informações divulgadas ao mercado e a combinação de dados.

Para a definição do Evento e Seleção dos Ativos, o ponto de partida foi a divulgação dos lucros/prejuízos em cada trimestre. Assim, a data que cada companhia divulgou as Demonstrações Contábeis na Comissão de Valores Mobiliários (CVM) foi a "Data Zero". A Janela de Eventos foi de 3 dias antes e de 3 dias depois da divulgação do lucro/prejuízo. Embora haja um componente subjetivo na definição do número de dias da Janela de Eventos, Benninga e Czaczkes (2008) argumentam que a parte significativa dos estudos recentes consideram Janelas de 3, 5 e 10 dias ao redor da data zero.

Os exames dos retornos diários observados, retornos diários esperados e retornos diários anormais ocorreram a partir das cotações de preços diários. Cabe ressaltar que o critério para seleção das companhias teve como base a disponibilidade de dados, sendo utilizadas apenas as séries de preços das ações ordinárias (ON).

Para determinar os retornos diários, primeiramente se estabeleceu a Janela de estimação, compreendendo 493 observações. Sendo o início dessa janela na $504^{a}$ observação anterior à data zero e a última observação da janela de estimação na $11^{a}$ observação anterior à data zero. O cálculo da janela de estimação foi construído tendo como base a determinação dos retornos diários observados, quais sejam: (i) retorno diário das ações $\left(R_{i}\right)$, na forma de capitalização continua; e (ii) retorno diário do mercado, 
representado pelo lbovespa $\left(R_{m}\right)$, também em capitalização continua. Os retornos diários observados foram determinados conforme a seguir:

$$
\begin{gathered}
R_{i}=\ln \left(P / P_{t-1}\right) \\
R m t=\ln \left(C / C_{t-1}\right)
\end{gathered}
$$

Em que,

$P_{\mathrm{f}}$ - é o preço da ação no momento t;

$P_{t-1}$ - é o preço da ação no momento t-1;

$C_{t}$ - é a cotação da Carteira de Mercado no momento † (lbovespa);

$\mathrm{C}_{\mathrm{t}-1}$ - é a cotação da Carteira de Mercado no momento t-1 (lbovespa);

In - representa a forma logarítmica utilizada para determinação dos retornos diários.

A estimação ocorreu por meio da aplicação de Mínimos Quadrados Ordinários (MQO) na forma de uma regressão linear simples comumente denominada de Modelo de Mercado, a qual tem a seguinte configuração:

$$
R_{i}=a_{i}+\beta_{i} R_{m t}+\varepsilon_{i}
$$

Os parâmetros a e $\beta$ foram usados para a determinação dos retornos diários esperados e retornos diários anormais. Dessa forma, os retornos diários esperados consistiram nos retornos que seriam produzidos pelo ativo em questão, a partir dos parâmetros a e $\beta$ estimados e dos retornos diários de mercado observados dentro da Janela de Eventos. Os retornos esperados foram operacionalizados conforme a seguir:

$$
E(R i \mid R m)=a i+\beta i R m t
$$

Os retornos diários anormais representam a diferença entre os retornos diários observados dados por $\mathrm{Ri}$ e os retornos diários esperados determinados por $E\left(R_{i} \mid R_{m}\right)$. Assim, operacionalizaram-se os retornos diários anormais $\left(A R_{i}\right)$ conforme equação abaixo. Portanto, o retorno diário anormal $\left(A R_{i}\right)$ representa um excedente positivo ou negativo.

$$
A R_{i}=\ln \left(P / P_{t-1}\right)-\left(a_{i}+\beta_{i} R_{m}\right)
$$

Em relação a estimação do retorno diário anormal e retorno anormal acumulado foram utilizados os seguintes procedimentos: $O$ retorno diário anormal foi determinado pela diferença entre o retorno diário observado e o retorno diário esperado (Equação 6). Os retornos anormais acumulados foram representados pela soma dos retornos anormais diários em períodos contínuos contidos na Janela de Eventos (Equação 7).

$$
\begin{aligned}
& A R_{i}=R_{i}-E\left(R_{i} / R_{m}\right) \\
& C A R_{i(t+,+2)}=\sum_{t=t l}^{2} A R_{i}
\end{aligned}
$$

O $C A R_{i(t 1, t 2)}$ representa o retorno anormal acumulado do ativo em análise, levando em consideração a extensão de dias a partir do primeiro $\left(t_{1}\right)$ até o último dia $\left(t_{2}\right)$ analisado. Por fim, os valores da estimação de $A R i$ e $C A R_{i(t 1,+2)}$ são o que determinam a variável dependente desta pesquisa, pois será com base nos retornos anormais que se verificará como o mercado reage à surpresa nos lucros.

Vale ressaltar, que dentre as inúmeras composições dos retornos anormais acumulados existentes ao redor do evento, foram escolhidas quatro métricas para fins de operacionalização da pesquisa: i) $A R[0]$ corresponde ao retorno anormal no dia da divulgação do lucro; ii) CAR[0;+3] corresponde ao retorno anormal acumulado após a divulgação do lucro; iii) CAR[-3;+3] corresponde ao retorno anormal acumulado dos três dias que antecedem a divulgação do lucro, bem como os três dias posteriores; vi) CAR[-3;-1] corresponde aos retornos anormais acumulados dos três dias que antecedem a divulgação do lucro.

\subsection{Varióvel independente}

A surpresa nos lucros foi computada pela diferença entre o Lucro por ação real (divulgado pela companhia) e o Lucro por ação previsto (último consenso dos analistas à data de divulgação dos lucros). A partir dos resultados foi possível classificar as surpresas em positivas e negativas. Surpresa positiva ocorre quando o resultado apresentar valor positivo, isto é, quando o resultado contábil da companhia for superior ao esperado pelos analistas. Por outro lado, quando o resultado do trimestre for menor que o esperado pelos analistas, a surpresa é negativa. Para efeito de análise, criouse a variável dicotômica SURP_D, na qual, as companhias que no trimestre apresentaram surpresa positiva serão classificadas com 1, se negativas, com 0 .

\subsection{Variável moderadora}

Em relação a variável moderadora, um investidor é considerado institucional quando se tratar de um acionista que atua com ativos sob gestão (Assets Under Management - AUM). Na plataforma Thomson Reuters ${ }^{\circledR}$ essa classificação é denominada "Investment Managers", que se trata de investidores institucionais (buy side) que estão na ponta compradora, tendo poder discricionário sob os ativos em gestão tanto nas decisões de compra como venda. Neste grupo de investidores estão: Bank and Trust; Foundation; Hedge Fund; Investment Advisor; Insurance Company; Pension Fund; Private Equity; Venture Capital; Investment 


\section{Advisor/Hedge Fund e Sovereign Wealth Fund.}

A representação da concentração dos investidores institucionais é feita por meio da variável "INST" que corresponde a razão da participação de ações ordinárias que os investidores institucionais detêm sobre as ações ordinárias da companhia. Trata-se de uma variável contínua de 0 a 1 , quanto mais próximo de 0 , menor a concentração de investidores institucionais, por outro lado, valores próximos a 1, indicam uma alta concentração de investidores institucionais tendo posse das ações ordinárias da companhia.

Uma variável possui efeito moderador, se a relação entre duas ou mais variáveis, $X$ e $Y$, apresentar variação em função dos níveis da moderação (Vieira, 2009; Whisman \& McClelland, 2005). Dessa forma, existe moderação, quando a nova variável oriunda da multiplicação entre a variável independente (SURP_D) e da variável moderadora (INST) for significativa na equação da regressão.

\subsection{Varióveis de Controle}

As variáveis de controle foram incluídas na regressão com intuito de buscar intervenientes do retorno anormal (como forma de isolar a influência que outras variáveis independentes poderiam exercer sobre a variável dependente). Na Tabela 1 estão identificadas as variáveis, as formas de cálculo e as referências de tais métricas.

Tabela 1. Definição das variáveis de controle

\begin{tabular}{|c|c|c|c|}
\hline Variável & Notação & Forma de Cálculo & Referências \\
\hline $\begin{array}{l}\text { Dificuldade } \\
\text { Financeira }\end{array}$ & ZALT & $\begin{array}{c}3,3 x_{1}+0,999 x_{1}+0,6 x_{3}+ \\
1,2 x_{4}+1,4 x_{4}\end{array}$ & $\begin{array}{l}\text { (Altman, 1968; Coelho } \\
\text { et al., 2017; Howe \& } \\
\text { Houston, 2016; Li et al., } \\
\text { 2017; Rosner, 2003; } \\
\text { Shahwan, 2015) }\end{array}$ \\
\hline $\begin{array}{c}\text { Grau de } \\
\text { Alavancagem }\end{array}$ & ALAV & $\begin{array}{l}\text { Passivo Total dividido } \\
\text { pelo Patrimônio Líquido }\end{array}$ & $\begin{array}{l}\text { (Barth et al.,2008; Klann } \\
\text { \& Beuren, 2015; Ribeiro \& } \\
\text { Colauto, 2016; Rodrigues } \\
\text { et al., 2019) }\end{array}$ \\
\hline Tamanho & LNAT & $\begin{array}{l}\text { Logaritmo natural dos } \\
\text { Ativos Totais }\end{array}$ & $\begin{array}{l}\text { (Klann \& Beuren, 2015; } \\
\text { Ribeiro \& Colauto, 2016; } \\
\text { Rodrigues et al., 2019) }\end{array}$ \\
\hline $\begin{array}{l}\text { Retorno sobre } \\
\text { os Ativos }\end{array}$ & ROA & $\begin{array}{l}\text { Lucro Líquido dividido } \\
\text { pelo Ativo Total }\end{array}$ & $\begin{array}{c}\text { (Gao \& Zhang, 2015; } \\
\text { González \& Garcia-Meca, } \\
\text { 2014; Ribeiro \& Colauto, } \\
\text { 2016; Rodrigues et al., } \\
\text { 2019) }\end{array}$ \\
\hline Market-to-Book & MTB & $\begin{array}{l}\text { Valor de mercado das } \\
\text { ações dividido valor } \\
\text { contábil do patrimônio } \\
\text { líquido }\end{array}$ & $\begin{array}{l}\text { (Cho et al., 2019; Gao \& } \\
\text { Zhang, 2015; Lento et al., } \\
\text { 2016; Potin et al., 2016) }\end{array}$ \\
\hline Idade & IDA & Anos de fundação & $\begin{array}{l}\text { (Bradshaw et al., 2012; } \\
\text { Cho et al..2019; } \\
\text { Dickinson, 2011; lima et } \\
\text { al., 2015) }\end{array}$ \\
\hline
\end{tabular}

Nota. $x_{1}=E B I T \div$ Total Assets; $x_{2}=$ Net Revenue $\div$ Total Assets; $x_{3}=$ Market Value of Equity $\div$ Total Liabilities; $x_{4}=$ Working Capital $\div$ Total Assets; $x_{5}=$ Retained Equity $\div$ Total Assets

\subsection{Procedimentos para Análise Inferencial}

A hipótese de pesquisa anunciada é de que a concentração de investidores institucionais modera negativamente a relação surpresa positiva dos lucros e retornos anormais. A Equação 8, refere-se ao modelo de regressão com a estrutura em painel:

$A R_{i t}=\beta_{0}+\beta_{1}$ SURP_ $D_{i t}+\beta_{2} I N S T_{i t}+\beta_{3} S U R P_{-} D_{i t}{ }^{*} I N S T_{i t}+$ $\beta 4 Z A L T_{i f}+\beta_{5} A L A V_{i t}+\beta_{6} L N A T_{i t}+\beta_{7} R O A_{i t}+\beta_{8} M T B_{i t}+\beta_{9}$ $I D A_{i t}+$ Setor $_{i}+$ Trim $_{i}+\varepsilon_{i t}(8)$

Em que:

$A R_{i t}$ - corresponde as métricas de retornos anormais AR[0], CAR[0;+3], CAR[-3;+3] e CAR[-3;-1] das ações da companhia i no período t;

$A R[0]$ - corresponde aos retornos anormais no dia da divulgação do lucro;

CAR[0;+3] - corresponde aos retornos anormais acumulados após a divulgação do lucro; CAR[-3;+3] corresponde aos retornos anormais acumulados nos três dias que antecedem a divulgação do lucro, bem como nos três dias posteriores;

CAR[-3;-1] - corresponde aos retornos anormais acumulados apenas dos três dias que antecedem a divulgação do lucro;

$\beta_{0}$ Intercepto da equação;

SURP_ $D_{n}$ - variável dummy da companhia i no período t que assume o valor "1" para surpresa positiva dos lucros e "0" para a surpresa negativa dos lucros;

$I N S T_{i t}$ - corresponde a concentração dos investidores institucionais da companhia i no período t;

$Z A L T_{i t}$ - nível de dificuldade financeira da companhia i no período t; $A L A V_{i t}$ - grau de alavancagem financeira da companhia i no período $\mathrm{t}$

$L N A T_{i t}$ - logaritmo dos ativos totais da companhia i no período t;

$R O A_{i t}$ - retorno sobre os ativos totais da companhia i no período t;

$M T B_{i t}$ - índice market-to-book da companhia i no período t;

$I D A_{i t}$ - idade da companhia i no período t;

Setor - variáveis dummy para controle setorial (2010 a 2018);

Trim $_{i}$ - variável dummy para controle de trimestre (2010 a 2018) e $\varepsilon_{i t}$-erro do modelo proposto.

A operacionalização da equação 8 ocorreu com base nas quatro métricas de Retornos Anormais: AR[0], CAR[0;+3], CAR[-3;+3] e CAR[-3;-1]. Ademais, duas análises são essenciais para compreensão dos resultados. A primeira trata-se do parâmetro $\beta_{1}$ que investiga a relação da surpresa positiva dos lucros em prever os retornos anormais, sendo que para $\circ$ teste de hipótese espera-se que $\beta_{1}>0$, isto é, uma surpresa positiva dos lucros deve aumentar os retornos anormais, tal como é evidenciado pela literatura (Alwathnani et al., 2017; Ball \& Brown, 1968; Galdi \& Lima, 2016; Martinez, 2006; Skinner \& Sloan, 2002).

A segunda e principal análise se referiu ao parâmetro $\beta_{3}$ resultante da interação entre a variável dummy surpresa 
positiva dos lucros (SURP_D) e a concentração de investidor institucional (INST). Espera-se que $\circ$ coeficiente deste parâmetro seja negativo, isto é $\beta_{3}<0$. A expectativa é de que a concentração de investidores institucionais atenue o efeito da surpresa positiva dos lucros sobre os retornos anormais. Como se trata de ações sofisticadas devido às características dos investidores, a precificação pode ocorrer de forma mais eficiente, diminuindo as chances de uma reação exagerada no retorno das ações quando o lucro divulgado se apresentar maior do que o estimado pelos analistas (surpresa positiva). As análises empíricas do estudo foram realizadas com recurso ao software de estatística SPSS 22 e STATA 13. Sendo considerado um nível de significância máximo de $5 \%$ em todos os testes de hipóteses. A detecção dos outliers ocorreu pelo processo de winsorização, a $1 \%$ no topo e na base dos dados (Alwathnani et al., 2017; Chiachio \& Martinez, 2019; Cho et al., 2018; Gao \& Zhang, 2015; Lorencini \& Costa, 2012).

\section{Descrição e Análise dos Resultados}

\subsection{Análise Descritiva dos Dados}

A Tabela 2 apresenta a análise descritiva das variáveis de pesquisa:

Tabela 2. Estatística descritiva das variáveis de pesquisa

\begin{tabular}{|c|c|c|c|c|c|}
\hline \multicolumn{6}{|c|}{ Painel (a) } \\
\hline $\begin{array}{c}\text { Variáveis } \\
\text { Quantitativas }\end{array}$ & Mínimo & Máximo & Média & Mediana & $\begin{array}{l}\text { Desvio } \\
\text { Padrão }\end{array}$ \\
\hline AR[0] & $-0,7040$ & 0,2152 & $-0,0006$ & $-0,0007$ & 0,0317 \\
\hline CAR $[0 ;+3]$ & $-0,3903$ & 0,3624 & $-0,0030$ & $-0,0010$ & 0,0598 \\
\hline CAR $[-3 ;+3]$ & $-0,4010$ & 0,3850 & $-0,0027$ & $-0,0024$ & 0,0690 \\
\hline CAR $[-3 ;-1]$ & $-0,2597$ & 0,2236 & 0,0003 & $-0,0003$ & 0,0373 \\
\hline INST & 0,0017 & 0,8522 & 0,3169 & 0,2570 & 0,2241 \\
\hline SURP & $-17,8667$ & 6,7333 & $-0,4606$ & $-0,0643$ & 2,6313 \\
\hline ZALT & $-0,3112$ & 9,3760 & 2,4580 & 1,8888 & 1,8505 \\
\hline ALAV & 0,0267 & 9,1984 & 1,2135 & 0,7560 & 1,4915 \\
\hline LNAT & 20,4957 & 27,0415 & 22,8229 & 22,6864 & 1,3003 \\
\hline ROA & $-0,0508$ & 0,0626 & 0,0109 & 0,0104 & 0,0181 \\
\hline MTB & 0,1683 & 15,9040 & 2,4258 & 1,5661 & 2,5850 \\
\hline IDA & 4,0000 & 99,0000 & 35,1201 & 33,00 & 23,0710 \\
\hline \multicolumn{6}{|c|}{ Painel (b) } \\
\hline \multirow[b]{2}{*}{$\begin{array}{l}\text { Surpresa nos } \\
\text { Lucros Dummy }\end{array}$} & \multicolumn{2}{|c|}{ Observações } & \multicolumn{3}{|c|}{ SURP } \\
\hline & Distribuição & $\%$ & Média & Mediana & $\begin{array}{l}\text { Estatística } \\
\text { U de Mann- } \\
\text { Whitney }\end{array}$ \\
\hline $\begin{array}{l}\text { Surpresa } \\
\text { Positiva "1" }\end{array}$ & 927 & $41 \%$ & 0,6824 & 0,2254 & \multirow{2}{*}{$0,000 * * *$} \\
\hline $\begin{array}{l}\text { Surpresa } \\
\text { Negativa "0" }\end{array}$ & 1337 & $59 \%$ & $-1,2531$ & $-0,3089$ & \\
\hline
\end{tabular}

Nota: AR[0] retornos anormais no dia da divulgação do lucro; CAR $[0 ;+3]$ retornos anormais acumulados após a divulgação do lucro; CAR[-3;+3] retornos anormais acumulados nos três dias que antecedem a divulgação do lucro, bem como nos três dias posteriores; CAR[-3;-1] retornos anormais acumulados nos três dias que antecedem a divulgação do lucro; INST concentração dos investidores institucionais; SURP surpresa nos lucros; LNAT logaritmo dos ativos totais; ROA retorno sobre os ativos totais; ALAV grau de alavancagem financeira; ZALT nível de dificuldade financeira; MTB índice Market-to-Book; IDA idade da companhia; ${ }^{* * *},{ }^{* *} \mathrm{e}$ * indica significância de 1\%, 5\% e 10\%.

As primeiras impressões relevam que as variáveis dependentes (retornos anormais) se apresentam de forma negativa. Isso quer dizer que, em média, a reposta do mercado diante da divulgação dos lucros trimestrais foi ruim, sendo a maior perda nos três dias após a data da divulgação do resultado contábil CAR[0;+3], em que os retornos anormais acumulados atingiram o valor de $-0,30$ pontos percentuais. Ressalta-se que a variável CAR[-3;-1] foi a única que não apresentou média negativa. Embora a média dos retornos anormais dessa variável seja ligeiramente positiva e sua mediana negativa, a janela de estimação contemplou apenas os três dias que antecederam a divulgação do resultado contábil, o que por sua vez, tende a demonstrar que o mercado não se antecipou a divulgação do lucro.

Uma possível explicação para a percepção negativa do mercado acerca da divulgação do resultado contábil ocorre pela análise da variável SURP. Percebe-se que a média da surpresa dos lucros foi computada como negativa, isto é, o resultado realizado no trimestre foi menor que 0 resultado esperado pelos analistas. Em média, o resultado contábil se revelou $46 \%$ menor do que a estimava dos analistas de mercado. Nesse contexto, tem-se um indicativo da força que a variável surpresa nos lucros apresenta sobre o retorno anormal.

O painel (b) da Tabela 2 utilizou a variável SURP de forma dicotômica, isto é, representa a surpresa de lucro como positiva e negativa. Os dados evidenciaram que menos da metade (41\%) das observações foram compostas por surpresas positivas, com resultados contábeis acima dos previstos pelos analistas. Ao analisar as médias de cada uma das surpresas (positiva e negativa), percebe-se que as positivas excedem a previsão dos analistas em $68,24 \%$, enquanto as surpresas negativas ficam aquém das previsões em $125 \%$, isto denota que as surpresas positivas são menos exacerbadas que as negativas. Tendo em vista que não será possível alcançar os resultados previstos, os gestores podem estar aumentando despesas ou reduzindo receitas com o intuito de criar reservas para serem revertidas e melhorar os resultados futuros (Healy, 1996). O teste de Mann-Whitney ( $U=000 ; p<0,01)$ apontou diferenças significativas entre esses dois grupos de surpresa. Em relação à variável moderadora INST, foi possível 
identificar que em média, os investidores institucionais representam cerca de $31,69 \%$ da estrutura de propriedade das companhias. Este dado reforça a crescente participação dos investidores institucionais no Brasil. Conforme González e García-Meca (2014) e Sousa (2017) os investidores institucionais nas companhias brasileiras aparecem com cerca de 28 e 24 pontos percentuais. Nesse sentido, cabe ressaltar a representatividade dos investidores institucionais no mercado brasileiro, isto porque, em comparação ao estudo de Lel (2019), em nível global, os investidores institucionais não chegaram a ultrapassar a marca de $10 \%$ de participação societária.

Tabela 3. Resultados das regressões em painel

\begin{tabular}{|c|c|c|c|c|c|c|c|c|c|}
\hline Explicativas & Dependentes & AR[O] & AR[0] & CAR $[0 ;+3]$ & CAR $[0 ;+3]$ & CAR $[-3 ;+3]$ & CAR $[-3 ;+3]$ & CAR[-3;-1] & CAR[-3;-1] \\
\hline \multirow[t]{2}{*}{ SURP_D } & Coef. & $0,0037^{* *}$ & 0,0029 & $0,0188^{* * *}$ & $0,0203^{* * *}$ & $0,0176 * * *$ & $0,0184^{* * *}$ & $-0,0014$ & $-0,0024$ \\
\hline & Std. Err. & 0,0016 & 0,0031 & 0,0031 & 0,0055 & 0,0034 & 0,0057 & 0,0017 & 0,0028 \\
\hline \multirow[t]{2}{*}{ INST } & Coef. & 0,0090 & 0,0081 & 0,0117 & 0,0136 & 0,0132 & 0,0143 & $-0,0048$ & $-0,0061$ \\
\hline & Std. Err. & 0,0074 & 0,0079 & 0,0166 & 0,0169 & 0,0183 & 0,0192 & 0,0040 & 0,0050 \\
\hline \multirow[t]{2}{*}{ SURP_D * INST } & Coef. & & 0,0025 & . & $-0,0051$ & . & .0,0027 & . & 0,0030 \\
\hline & Std. Err. & . & 0,0070 & . & 0,0129 & . & 0,0150 & - & 0,0071 \\
\hline \multirow[t]{2}{*}{ ZALT } & Coef. & $-0,0025^{*}$ & $-0,0025^{*}$ & $-0,0080 * * *$ & $-0,0079 * * *$ & $-0,0094^{* * *}$ & $-0,0094 * * *$ & $-0,0015^{* *}$ & $-0,0016^{* *}$ \\
\hline & Std. Err. & 0,0014 & 0,0014 & 0,0018 & 0,0018 & 0,0024 & 0,0024 & 0,0007 & 0,0007 \\
\hline \multirow[t]{2}{*}{ ALAV } & Coef. & $-0,0001$ & $-0,0001$ & $0,0053^{* * *}$ & $0,0052^{* * *}$ & $0,0074^{* * *}$ & $0,0074^{* * *}$ & 0,0009 & 0,0009 \\
\hline & Std.Err. & 0,0014 & 0,0012 & 0,0017 & 0,0017 & 0,0026 & 0,0026 & 0,0007 & 0,0007 \\
\hline \multirow[t]{2}{*}{ INAT } & Coef. & $-0,0067 * *$ & $-0,0067 * *$ & $-0,0072$ & $-0,0071$ & $-0,0100$ & $-0,0100$ & $-0,0007$ & 0,0007 \\
\hline & Std. Err. & 0,0033 & 0,0033 & 0,0056 & 0,0056 & 0,0062 & 0,0062 & 0,0009 & 0,0009 \\
\hline \multirow[t]{2}{*}{$\mathrm{ROA}$} & Coef. & 0,1554 & $0,1557^{*}$ & $0,4749 * * *$ & $0,4743^{* * *}$ & $0,7011^{* * *}$ & $0,7008^{* * *}$ & $0,1594^{* * *}$ & $0,1603^{* * *}$ \\
\hline & Std.Err. & 0,09358 & 0,0937 & 0,1360 & 0,1359 & 0,1525 & 0,1526 & 0,0618 & 0,0619 \\
\hline \multirow[t]{2}{*}{ MTB } & Coef. & $-0,0005$ & $-0,0005$ & $-0,0037^{* * *}$ & $-0,0037^{* * *}$ & $-0,0059 * * *$ & $-0,0059 * * *$ & $-0,0009 * *$ & $-0,0009^{* *}$ \\
\hline & Std. Err. & 0,0009 & 0,0009 & 0,0019 & 0,0011 & 0,0012 & 0,0013 & 0,0005 & 0,0005 \\
\hline \multirow[t]{2}{*}{ IDA } & Coef. & $-0,0049 * * *$ & $-0,0048 * * *$ & $-0,0124^{* * *}$ & $-0,0124^{* * *}$ & $-0,0167^{* * *}$ & $-0,0167^{* * *}$ & 0,0000 & 0,0000 \\
\hline & Std. Err. & 0,0013 & 0,0013 & 0,0043 & 0,0042 & 0,0043 & 0,0042 & 0,0000 & 0,0000 \\
\hline \multirow[t]{2}{*}{ Constante } & Coef. & $0,3456^{* * *}$ & $0,3459 * * *$ & $0,6524 * * *$ & $0,6517 * * *$ & $0,8963^{* * *}$ & $0,8960 * * *$ & $0,0349 *$ & $0,0355^{*}$ \\
\hline & Std.Err. & 0,0932 & 0,0929 & 0,2137 & 0,2117 & 0,2172 & 0,2160 & 0,0206 & 0,0206 \\
\hline \multicolumn{2}{|c|}{ Observações } & 2264 & 2264 & 2264 & 2264 & 2264 & 2264 & 2264 & 2264 \\
\hline \multicolumn{2}{|c|}{ Set e Trim } & sim & Sim & sim & Sim & sim & Sim & sim & Sim \\
\hline \multicolumn{2}{|c|}{ Teste Painel Chow } & $1,290 * * *$ & $1,290 * * *$ & $1,550 * * *$ & $1,550^{* * *}$ & $1,450 * * *$ & $1,440^{* * *}$ & 1,200 & 1,190 \\
\hline \multicolumn{2}{|c|}{ Teste Painel Breusch Pagan } & 0,000 & 0,000 & 1,970 & 2,020 & 0,000 & 0,000 & 0,00 & 0,00 \\
\hline \multicolumn{2}{|c|}{ Teste Painel Hausman } & $165,97^{* * *}$ & $218,26 * * *$ & $84,440^{* * *}$ & $77,90 * * *$ & $79,570^{* * *}$ & $80,34 * * *$ & 51,26 & 51,24 \\
\hline \multicolumn{2}{|c|}{ Tipo Painel } & Fixo & Fixo & Fixo & Fixo & Fixo & Fixo & Pooled & Pooled \\
\hline \multicolumn{2}{|c|}{ VIF médio } & 2,47 & 2,55 & 2,47 & 2,55 & 2,47 & 2,55 & 2,47 & 2,55 \\
\hline \multicolumn{2}{|c|}{ Normalidade Jarque-Bera } & $1.2 \mathrm{e}+06 * * *$ & $1.2 \mathrm{e}+06 * * *$ & $1594^{* * *}$ & $1605^{* * *}$ & $911,6^{* * *}$ & $916,5^{* * *}$ & $1612^{* * *}$ & $1607 * * *$ \\
\hline \multicolumn{2}{|c|}{ Heteroc. Wald/Breusch-Pagan } & $11369,85^{* * *}$ & $11112,10^{* * *}$ & $7.5 \mathrm{e}+29 * * *$ & $3.0 \mathrm{e}+30 * * *$ & $12044,83^{* * *}$ & $12156,84^{* * *}$ & 0,3313 & 0,3567 \\
\hline \multicolumn{2}{|c|}{ Autocorrelação Wooldridge } & 0,441 & 0,351 & 0,082 & 0,075 & 0,691 & 0,690 & 0,329 & 0,304 \\
\hline \multicolumn{2}{|c|}{ Teste F } & $3,45^{* * *}$ & $3,50 * * *$ & $5,81^{* * *}$ & $5,64 * * *$ & $8,59 * * *$ & $8,45^{* * *}$ & $1,42^{* *}$ & $1,39 * *$ \\
\hline \multicolumn{2}{|c|}{ R2 within } & 0,0327 & 0,0328 & 0,0733 & 0,0734 & 0,0743 & 0,0743 & . & . \\
\hline \multicolumn{2}{|c|}{ R2 between } & 0,0014 & 0,0014 & 0,0011 & 0,0011 & 0,0021 & 0,0021 & . & . \\
\hline \multicolumn{2}{|c|}{ R2 overall } & 0,0001 & 0,0001 & 0,0000 & 0,0000 & 0,0000 & 0,0000 & 0,0090 & 0,0086 \\
\hline
\end{tabular}

Nota: AR[0] retornos anormais no dia da divulgação do lucro; CAR[0;+3] retornos anormais acumulados após a divulgação do lucro; CAR[-3;+3] retornos anormais acumulados nos três dias que antecedem a divulgação do lucro, bem como nos três dias posteriores; CAR[-3;-1] retornos anormais acumulados nos três dias que antecedem a divulgação do lucro; SUR_D variável dummy que assume o valor "1" para surpresa positiva do lucro e " $O$ " para a surpresa negativa do lucro; INST concentração dos investidores institucionais; LNAT logaritmo dos ativos totais; ROA retorno sobre os ativos totais; ALAV grau de alavancagem financeira; ZALT nível de dificuldade financeira; MTB índice Market-to-book; IDA idade da companhia; Os dados não apresentaram multicolinearidade: VIF<5; O teste de Jarque-Bera confirmou a não normalidade dos resíduos, contudo, diante do tamanho da amostra analisada, assume-se a normalidade assintótica, respaldada no teorema do limite central (Wooldridge, 2006); O teste Wooldridge apontou a não existência de autocorrelação entre os resíduos da regressão tendo em vista que o p-valor foi maior que 0,05; O teste de Wald diagnosticou heterocedasticidade no painel com efeitos fixos, por isso a computação dos estimadores ocorreu considerando estimadores robustos a heterocedasticidade; ***, ** e* indica significância de 1\%, 5\% e $10 \%$. 
Conforme apontado pela Tabela 3, a variável de interação SURP_D* INST não se apresentou significativa, denotando que a concentração dos investidores institucionais não consegue alterar a direção ou a força que a surpresa positiva dos lucros causa nos retornos anormais.

Acreditava-se que esta interação pudesse ser negativa, isto é, os investidores institucionais teriam condições de revisar com maior agilidade a diferença entre o lucro divulgado e a sua expectativa, e portando, o fator surpresa positiva não seria tão impactante para as companhias com maior concentração de investidores institucionais, porém a significância estatística não proporcionou a confirmação da hipótese de pesquisa.

Desse modo, ficou evidente a violação da HME em sua forma semiforte. Notou-se que os preços das ações negociadas não refletem de maneira completa e instantânea, toda informação relevante e disponível a respeito das referidas ações, haja vista que a surpresa dos lucros gerou retornos anormais.

Por outro lado, era esperado que um maior peso de investidores sofisticados da estrutura de propriedade das companhias pudesse melhorar ou mesmo corrigir a precificação das ações no momento da surpresa dos lucros. Segundo Green et al. (2011) a figura do investidor institucional foi capaz de reduz as anomalias dos accruals no mercado americano. De acordo com liu (2018) os investidores institucionais podem apresentar habilidades para identificar informações relacionadas a qualidade do lucro.

$O$ pressuposto de que os investidores institucionais seriam suficientemente sofisticados para analisar todo o fluxo de informação contábil divulgada pelas companhias, no que tange aos aspectos da surpresa do lucro, e que efetuariam análises econômico-financeiras para corrigir a reação exagerada no preço das ações, no momento da divulgação do lucro trimestral, não foi observado.

Os resultados para a amostra em análise denotam que a concentração dos investidores institucionais no quadro de acionistas da companhia não foi suficiente para mitigar os retornos anormais ocorridos diante da surpresa positiva de lucro. A falta de significância estatística também foi compartilhada em Sen (2009), quando concluíram que a surpresa de lucro não foi precificada de forma correta pelo mercado indiano e que os investidores institucionais também não conseguiram atenuar essa anomalia.

Alguns conjecturadores podem ajudar a entender os resultados obtidos, uma delas é que os investidores no Brasil apresentam orientação de investimento para o curto prazo. $\mathrm{Na}$ revisão de literatura feita por Ferri e Soares (2009), não se descarta a probabilidade de os executivos terem um comportamento míope quando existirem certos perfis de investidores institucionais, isto é, adotar uma postura de administrador de carteira, e não de proprietário. Assim, uma mudança na expectativa futura da empresa causada pela divulgação de um lucro não esperado pode ser capaz de mudar a posição dos investidores, inclusive os institucionais, o que por sua vez refletirá no preço das ações.

Convém ressaltar que a surpresa de lucro foi um determinante significativo para três métricas de retornos anormais. Os resultados atestaram que a surpresa positiva de lucro gera efeitos positivos nos valores de mercado dos títulos das companhias, isto é, a divulgação de um lucro acima da expectativa dos analistas aumenta os retornos anormais no dia da divulgação do lucro AR[0], nos dias subsequentes CAR $[0 ;+3]$, bem como nos retornos anormais acumulados em torno da divulgação do lucro CAR[-3;+3].

Esses achados seguem a linha de estudos vanguardistas como o de Latané e Jones (1977), Jones et al. (1984) e Jones et al. (1985), que comprovaram que o mercado brasileiro também reage de forma atrasada ao revisar os preços das ações diante das surpresas de lucros. A não significância foi encontrada apenas para a variável dependente CAR[-3;-1]. A ideia dessa última variável foi testar se o mercado tinha conhecimento do lucro por antecipação, isto é, se o mercado poderia reagir às surpresas de lucros antes que a informação se tornasse pública. No entanto, conforme expresso na Tabela 3 o coeficiente da surpresa positiva de lucro não foi significativo, descartando essa possibilidade.

Além da surpresa dos lucros, o mercado também reagiv a outras variáveis no momento da divulgação dos demonstrativos contábeis. A variável de controle ZALT, demonstrou que quanto mais crítica é a situação financeira da companhia, menores são as taxas de retornos anormais. Por outro lado, quando se analisou o efeito da variável ALAV sobre os retornos anormais nas métricas CAR[0;+3] e CAR[-3;+3], percebeu-se que o mercado não reprimiu as companhias mais arriscadas em termos de endividamento.

Pelo contrário, as companhias com maiores níveis de dependência de recursos de terceiros apresentaram retornos anormais positivos e estatisticamente significativos. Comparando-se os efeitos de ZALT e ALAV sobre os retornos anormais foi possível constatar que 0 mercado consegue discernir que o endividamento pode não ser a principal causa dos problemas financeiros da companhia. Ademais, não se descarta a possibilidade de o mercado estar validando os benefícios do custo da dívida com terceiros para obtenção de lucro. 
Ainda em relação às variáveis de controle, destaca-se a influência positiva e estatisticamente significativa do ROA sobre o retorno anormal. Em praticamente todas as regressões constante na Tabela 3 percebe-se que a melhor rentabilidade do ativo refletiu no aumento dos retornos anormais. Esses resultados reafirmam a importância da companhia gerar resultados positivos, pois demonstra que as ações com potencial de geração de lucros causam reações exageradas tanto no momento da divulgação dos resultados contábeis como nos três dias que antecedem a divulgação do lucro CAR[-3;-1].

Sobre a variável IDA, os dados apontaram que a idade da companhia foi outro determinante que interferiu no retorno anormal das ações. O mercado reagiu negativamente para as companhias com mais anos de fundação, isto é, no momento da divulgação dos resultados contábeis há um bônus pago para as companhias mais novas. Consequentemente, o resultado indica que os investidores no mercado brasileiro podem estar mais interessados em ações que apresentem crescimento mais acelerado.

Por último, avaliou-se o comportamento das variáveis MTB e LNAT. Os dados revelaram que as ações mais valorizadas pelo mercado em relação ao valor patrimonial da companhia, ou seja, as ações com maior pontuação de MTB, são as que apresentaram menores retornos anormais. Exceto no modelo $A R[0]$, na qual a variável MTB não se revelou estatisticamente significativa. Em relação ao tamanho da companhia, representando pela variável LNAT, as inferências dos resultados são imprecisas, apesar de sua relação negativa com os retornos anormais, isto é, quanto maior a companhia, menor é o retorno. Não obstante, os resultados se configuram como inconclusivos, pois em apenas uma das métricas de retornos anormais o log dos ativos se apresentou significante, mesmo assim, acima de $5 \%$.

\section{Conclusões}

Os resultados do estudo apontam que o mercado brasileiro falha em precificar a informação da surpresa nos lucros de forma instantânea, provocando por sua vez, um excesso de retorno. Com base nas regressões com dados em painel, constatou-se que a surpresa nos lucros é um preditor significativo dos retornos anormais. Assim, resultados contábeis acima dos previstos pelos analistas (surpresa positiva) são capazes de gerar retornos anormais positivos. $O$ contrário também é válido, resultados abaixo das expectativas dos analistas (surpresa negativa) interferem negativamente nos retornos anormais no curto prazo.
Os resultados evidenciaram que o mercado brasileiro não antecipou o efeito da surpresa nos lucros antes da divulgação dos demonstrativos contábeis, tendo em vista a falta de significância estatística entre SURP_D e CAR[-3;-1]. Percebese que a surpresas nos lucros somente influenciou os retornos anormais após a divulgação pública dos demonstrativos contábeis.

Buscou-se também compreender se o atraso na precificação das ações estava relacionado com a presença da sofisticação dos investidores na estrutura de propriedade da companhia. A hipótese desta pesquisa partiu da premissa que a anomalia de precificação dos ativos seria atenuada pela presença de investidores institucionais. Acreditavase que a maior concentração de investidores institucionais pudesse moderar negativamente a relação surpresa positiva dos lucros e retornos anormais. No entanto, a ausência de significância do coeficiente de interação SURP_D*INST não permitiu confirmar a hipótese de que uma alta concentração de investidores institucionais atenua o efeito da surpresa positiva dos lucros sobre os retornos anormais.

Por fim, no mercado brasileiro a surpresa nos lucros é responsável por parte das anomalias no preço das ações. Apesar do excesso de retorno ser justificado por razões econômicas, ou seja, a surpresa nos lucros apresenta conteúdo informacional com relação aos lucros futuros, não se descarta a possibilidade de investidores formarem carteiras de ativos para explorar esta relativa má-precificação. Ademais, as características de sofisticação financeira do investidor institucional parecem não ser suficientes para conter os atrasos ou vieses na interpretação das informações divulgadas sobre - lucro, o que por sua vez, possibilita espaço para ganhos anormais diante de uma surpresa positiva de lucros.

Quanto às limitações da pesquisa, é preciso reconhecer que os resultados estão circunscritos às variáveis empregadas no estudo e às companhias que constituíram a amostra. Sugerese para pesquisas futuras explorar tais limitações, assim como aumentar o número de variáveis de controle como forma de neutralizar outras influências do ambiente nos resultados. Poderiam ser investigadas as classificações internas de investidores institucionais, tais como: fundos de pensão, bancos e seguradoras, fundo de hedge, dentre outros, na tentativa de identificar se determinado tipo de investidor modera a relação surpresa-retorno. Outra possiblidade de estudo que agregaria maiores conhecimentos e permitiria ratificar estes resultados é a utilização de uma metodologia de portfólio/carteiras, bem como o aumento da janela de eventos dos retornos anormais com vista a verificar o comportamento das ações no longo prazo. 


\section{Referências}

Altman, E. I. (1968). Financial ratios, discriminant analysis and the prediction of corporate bankruptcy. The Journal of Finance, 23(4), 589-609. DOI: $10.1111 /$ i.1540-6261.1968. tb00843.x

Alwathnani, A. M., Dubofsky, D. A., \& Al-Zoubi, H. A. (2017). Under-or-overreaction: Market responses to announcements of earnings surprises. International Review of Financial Analysis, 52, 160-171. DOI: https://doi.org/10.1016/i. irfa.2017.07.006

Ball, R., \& Brown, P. (1968). An Empirical Evaluation of Accounting Income Numbers. Journal of Accounting Research, 6(2), 159-178. DOI: 10.2307/2490232

Barros, C. M. E., Lopes, I. F., \& de Almeida, L. B. (2019). Efeito contágio da operação carne fraca sobre o valor das ações dos principais players do mercado de proteínas do Brasil e do México. Enfoque, 38(1), 105. DOl:10.4025/ enfoque.v38i1.39966

Barth, M. E., Landsman, W. R., \& Lang, M. H. (2008). International Accounting Standards and Accounting Quality. Journal of Accounting Research, 46(3), 467-498. DOI: 10.1111/j.1475-679X.2008.00287.x

Bartov, E., Givoly, D., \& Hayn, C. (2002). The rewards to meeting or beating earnings expectations. Journal of Accounting and Economics, 33(2), 173-204. DOI: http:// dx.doi.org/10.1016/S0165-4101(02)00045-9

Beaver, W. H., Clarke, R., \& Wright, W. F. (1979). The Association between Unsystematic Security Returns and the Magnitude of Earnings Forecast Errors. Journal of Accounting Research, 17(2), 316-340. DOI: 10.2307/2490507

Belo, N. M., \& Brasil, H. G. (2006). Assimetria informacional e eficiência semiforte do mercado. Revista de Administração de Empresas, 46, 48-57. DOI: 10.1590/S003475902006000500004

Benninga, S., \& Czaczkes, B. (2008). Financial Modeling Cambridge, Massachusetts: The MIT Press.

Bernard, V. L., \& Thomas, J. K. (1989). Post-EarningsAnnouncement Drift: Delayed Price Response or Risk Premium? Journal of Accounting Research, 27, 1-36. DOI: $10.2307 / 2491062$

Boehmer, E., \& Kelley, E. K. (2009). Institutional Investors and the Informational Efficiency of Prices. The Review of Financial Studies, 22(9), 3563-3594. DOI: 10.1093/rfs/hhp028

Botelho, L. (2019) Quem são os investidores institucionais e como influenciam o mercado/Interviewer: $R$. SpaceMoney. Investidores. encurtador.com.br/dwWW6

Bradshaw, M. T., Drake, M. S., Myers, J. N., \& Myers, L. A. (2012). A re-examination of analysts' superiority over timeseries forecasts of annual earnings. Review of Accounting Studies, 17(4), 944-968. DOli: 10.1007/s $11142-012-9185$ 8

Brown, L. D. (1997). Earnings Surprise Research: Synthesis and Perspectives. Financial Analysts Journal, 53(2), 13-19. DOI: 10.2469/fai.v53.n2.2067

Champbell, J. J., Lo, A. W., \& MacKinlay, A. C. (1997). The econometrics of financial markets: Princeton University press.

Chiachio, V. F. d. O., \& Martinez, A. L. (2019). Efeitos do Modelo de Fleuriet e Índices de Liquidez na Agressividade Tributária. Revista de Administração Contemporânea, 23(2), 160-181. DOI:10.1590/1982-7849rac2019180234

Cho, S. J., Chung, C. Y., \& Liu, C. (2018). Does Institutional Blockholder Short-Termism Lead to Managerial Myopia? Evidence from Income Smoothing. International Review of Finance. DOI: 10.1111/irfi.12219

Cho, S. J., Chung, C. Y., \& Liu, C. (2019). Does Institutional Blockholder Short-Termism Lead to Managerial Myopia? Evidence from Income Smoothing. International Review of Finance, 19(3), 693-703. DOI: 10.1111/irfi.12219

Chudek, M., Truong, C., \& Veeraraghavan, M. (2011). Is trading on earnings surprises a profitable strategy? Canadian evidence. Journal of International Financial Markets, Institutions and Money, 21(5), 832-850. DOI: 10.1016/j. inffin.2011 1.06.004

Coelho, E. G., Barros, C. M. E., Scherer, L. M., \& Colauto, R. D. (2017). Gerenciamento de resultado em empresas insolventes: um estudo com os países do Brics. Enfoque: Reflexão Contábil, 36(2), 95-113. DOI: 10.4025/enfoque. v36i2.31765

Dickinson, V. (2011). Cash flow patterns as a proxy for firm life cycle. The Accounting Review, 86(6), 1969-1994. DOI: 10.2308/acer-10130

Ferri, M. d. S., \& Soares, R. O. (2009). Investidores 
institucionais e o foco no curto prazo: um estudo nas empresas negociadas na Bovespa. Contabilidade Vista \& Revista, 20(4), 15-30.

Foster, G., Olsen, C., \& Shevlin, T. (1984). Earnings Releases, Anomalies, and the Behavior of Security Returns. The Accounting Review, 59(4), 574-603.

Galdi, F. C., \& Lima, V. S. M. (2016). Value \& Growth Investing and PEAD in Brazil. Brazilian Review of Finance, 14(4), 1-27. DOI: 1679-0731

Gao, L., \& Zhang, J. H. (2015). Firms' earnings smoothing, corporate social responsibility, and valuation. Journal of Corporate Finance, 32, 108-127. DOI: https://doi. org/10.1016/i.jcorpfin.2015.03.004

González, J. S., \& García-Meca, E. (2014). Does corporate governance influence earnings management in Latin American markets? Journal of Business Ethics, 121(3), 419-440. DOI: 10.1007/s10551-013-1700-8.

Graham, J. R., Harvey, C. R., \& Rajgopal, S. (2005). The economic implications of corporate financial reporting. Journal of Accounting and Economics, 4O(1), 3-73. DOl: https://doi. org/10.1016/i.jacceco.2005.01.002

Green, J., Hand, J. R., \& Soliman, M. T. (2011). Going, going, gone? The apparent demise of the accruals anomaly. Management Science, 57(5), 797-816. DOI: 10.1287/ mnsc. 1110.1320

Healy, P. (1996). Discussion of a market-based evaluation of discretionary accrual models. Journal of Accounting Research, 34, 107-115. DOI: 10.2307/2491428

Hirshleifer, D., Hou, K., \& Teoh, S. H. (2012). The accrual anomaly: risk or mispricing? Management Science, 58(2), 320-335. DOI: 10.1287/MNSC. 1100.1289

Howe, J. S., \& Houston, R. (2016). Earnings management, earnings surprises, and distressed firms. Accounting and Finance Research, 5(1), 64-87. DOI: 10.5430/afr.v5n 1 p64

Jiang, W., Lee, P., \& Anandarajan, A. (2008). The association between corporate governance and earnings quality: Further evidence using the GOV-Score. Advances in Accounting, 24(2), 191-201. DOI: hitps://doi.org/10.1016/i. adiac.2008.08.011

Jones, C. P., Rendleman, R. J., \& Latané, H. A. (1984). Stock returns and SUEs during the 1970's. The Journal of
Portfolio Management, 10(2), 18-22. DOI: 10.3905/ jpm. 1984.408953.

Jones, C. P., Rendleman, R. J., \& Latané, H. A. (1985). Earnings announcements. The Journal of Portfolio Management, 11 (3), 28. DOI: 10.3905/jpm. 1985.409002.

Klann, R. C., \& Beuren, I. M. (2015). Impacto da convergencia contabil internacional na suavizacao de resultados em empresas Brasileiras. Brazilian Business Review, 12(2), 1. DOI: 10.15728/bbr.2015.12.2.1

Latané, H. A., \& Jones, C. P. (1977). Standardized unexpected earnings a progress report. The Journal of Finance, 32(5), 1457-1465. DOI: 10.1111/j.1540-6261.1977.tb03347.x

Lel, U. (2019). The role of foreign institutional investors in restraining earnings management activities across countries. Journal of International Business Studies, 50(6), 895-922. DOI: 10.1057 / s41267-018-0195-z

Lento, C., Cotter, J., \& Tutticci, I. (2016). Does the market price the nature and extent of earnings management for firms that beat their earnings benchmark? Australian Journal of Management, 41(4), 633-655. DOI: 10.1177/0312896216641600

Li, K., Lockwood, J., \& Miao, H. (2017). Risk-shifting, equity risk, and the distress puzzle. Journal of Corporate Finance, 44, 275-288. DOI: 10.1016/i.jcorpfin.2017.04.003

Lima, A. S. d., Carvalho, E. V. A. d., Paulo, E., \& Girão, L. F. d. A. P. (2015). Estágios do ciclo de vida e qualidade das informações contábeis no Brasil. Revista de Administração Contemporânea, 19(3), 398-418. DOI: 10.1590/19827849rac20151711

Lima, G. A. S. F. d., Yamamoto, M. M., Lima, I. S., \& Malacrida, M. J. C. (2008). Um estudo da eficiência informacional do mercado acionário brasileiro. Revista de Informação Contábil, 2(1), 1-18. DOI: https://doi.org/10.34629/ufpeiscal/1982-3967.2008.v2.1-18

Liu, S. (2018). Earnings management and institutional investor trading prior to earnings announcements. China Finance Review International. DOI: 10.1 108/CFRI-01-2018-0010

Lorencini, F. D., \& Costa, F. M. d. (2012). Escolhas contábeis no Brasil: identificação das características das companhias que optaram pela manutenção versus baixa dos saldos do ativo diferido. Revista Contabilidade \& Finanças-USP, 23(58), 52-64. DOI: 10.1590/S1519-70772012000100004 
Martinez, A. L. (2006). Como o mercado de capitais brasileiro reage a surpresa nos lucros? REAd - Revista Eletrônica de Administração, 12(3), 1-23.

Martins, V. G., Monte, P. A., \& Machado, M. A. V. (2019). Análise das Hipóteses de Risco e Mispricing dos Accruals: evidências do Brasil. RBGN: Revista Brasileira de Gestão de Negócios, 21(1), 169-186. DOI:10.7819/rbgn.v21i1.3969

Paulo, E., Sarlo Neto, A., \& Santos, M. A. C. d. (2013). Reação do preço das ações e intempestividade informacional do lucro contábil trimestral no Brasil. ASAA-Advances in Scientific and Applied Accounting, 5(1), 54-79. DOI: 10.14392/ASAA/2012050103

Pimentel, R. C. (2015). Lucros Inesperados, Retorno das Ações e Risco no Mercado de Capitais Brasileiro. Revista Contabilidade \& Finanças, 26(69), 290-303. DOI: $10.1590 / 1808-057 \times 201501270$

Potin, S. A., Bortolon, P. M., \& Sarlo Neto, A. (2016). Hedge Accounting no Mercado Acionário Brasileiro: Efeitos na Qualidade da Informação Contábil, Disclosure e Assimetria de Informação. Revista Contabilidade \& Finanças - USP, 27(71), 202-2016. DOI: 10.1590/1808-057×201602430

Ribeiro, F., \& Colauto, D. R. (2016). A relação entre board interlocking e as práticas de suavização de resultados. Revista Contabilidade \& Finanças-USP, 27(70), 55-66. DOI: $10.1590 / 1808-057 \times 201501320$

Rodrigues, R. M. R. C., Melo, C. L. L., \& Paulo, E. (2019). Gerenciamento de Resultados e Nível dos Accruals Discricionários Trimestrais no Mercado Acionário Brasileiro. BBR. Brazilian Business Review, 16(3), 297-314. DOI: 10.15728/bbr.2019.16.3.6

Rosner, R. L. (2003). Earnings Manipulation in Failing Firms. Contemporary Accounting Research, 20(2), 361-408. DOI: 10.1506/8EVN-9KRB-3AE4-EE8 1

Sarlo Neto, A., Teixeira, A. J. C., Loss, L., \& Lopes, A. B. (2005). O diferencial no impacto dos resultados contábeis nas ações ordinárias e preferenciais no mercado brasileiro. Revista Contabilidade \& Finanças, 16(37), 46-58.

\section{DOI: 10.1590/S1519-70772005000100004}

Schimmer, M., Levchenko, A., \& Müller, S. (2015). Event Study Tools (Research Apps), St. Gallen. Disponível em http://www.eventstudytools. com. Accesso em 09 outubro de 2019.

Sen, K. (2009). Earnings surprise and sophisticated investor preferences in India. Journal of Contemporary Accounting \& Economics, 5(1), 1-19. DOI: doi.org/10.1016/j. jcae.2008.11.001

Shahwan, T. M. (2015). The effects of corporate governance on financial performance and financial distress: evidence from Egypt. Corporate Governance: The international journal of business in society, 15(5), 641-662. DOI:10.1108/CG$11-2014-0140$

Skinner, D., \& Sloan, R. (2002). Earnings Surprises, Growth Expectations, and Stock Returns or Don't Let an Earnings Torpedo Sink Your Portfolio. Review of Accounting Studies, 7(2-3), 289-312. DOI: 10.1023/A:1020294523516

Sousa, E. P. d. (2017). Evidências internacionais dos efeitos da atuação de investidores institucionais na anomalia dos accruals. Paper presented at the XVII International Conference in Accounting, São Paulo/SP.

Vasconcelos, L. N., \& Martins, O. S. (2020). Governança via negociação de ações no brasil: evidências com investidores institucionais. RAM. Revista de Administração Mackenzie, 21(6), 1-31. DOI:10.1590/1678-6971/eRAMD200046

Vieira, V. A. (2009). Moderação, mediação, moderadoramediadora e efeitos indiretos em modelagem de equações estruturais: uma aplicação no modelo de desconfirmação de expectativas. Revista de Administração-RAUSP, 44(1), 17-33.

Whisman, M. A., \& McClelland, G. H. (2005). Designing, testing, and interpreting interactions and moderator effects in family research. Journal of family psychology, 19(1), 111. DOI: 10.1037/0893-3200.19.1.111

Wooldridge, J. M. (2006). Introductory econometrics: A modern approach, 3rd. New York: Thomson. 